\title{
Derivation of Induced Pluripotent Stem Cells from Human Fibroblasts Using a Non-integrative System in Feeder-free Conditions
}

Alvaro A. Beltran¹, Sarahi G. Molina ${ }^{2}$ and Adriana S. Beltran ${ }^{2,3, *}$

${ }^{1}$ Department of Neuroscience, University of North Carolina, Chapel Hill, NC 27599, USA; ${ }^{2}$ Human Pluripotent Stem Cell Core, University of North Carolina, Chapel Hill, NC 27599, USA; ${ }^{3}$ Department of Pharmacology, University of North Carolina, Chapel Hill, NC 27599, USA

*For correspondence: beltran@med.unc.edu

[Abstract] Induced pluripotent stem cells (iPSCs) are genetically reprogrammed somatic cells that exhibit features identical to those of embryonic stem cells (ESCs). Multiple approaches are available to derive iPSCs, among which the Sendai virus is the most effective at reprogramming different cell types. Here we describe a rapid, efficient, safe, and reliable approach to reprogram human fibroblasts into iPSCs that are compatible with future iPSCs uses such as genome editing and differentiation to a transplantable cell type.

Keywords: Feeder-free, Fibroblasts, Sendai virus, Induced pluripotent stem cells, Transgene-free

[Background] Induced pluripotent stem cells (iPSCs) are genetically reprogrammed adult cells that exhibit morphological and functional qualities remarkably similar to those of embryonic stem cells (ESCs) (Takahashi and Yamanaka, 2006; Yu et al., 2007). They offer a great opportunity not only for disease modeling, but for the development of therapeutic strategies for pathologies that involve tissue degeneration. Furthermore, the iPSCs promise relies on a safe replenishable cell source derived in chemically defined media and free of random DNA integration.

Reprogramming somatic cells into iPSCs requires the forced expression of transcription factors that support the pluripotent state, including OCT4, SOX2, KLF4, C-MYC, NANOG, and LIN-28 (Takahashi and Yamanaka, 2006; Takahashi et al., 2007; Yu et al., 2007). Multiple approaches are available to deliver the transcription factors into the cells, including those that require integration into the host chromosomes (Takahashi and Yamanaka, 2006; Kane et al., 2010). Exogenous DNA integration can lead to unpredictable effects on the quality of the cells and safety after transplantation. Other approaches include DNA based vectors that exist episomally (Yu et al., 2011; Weltner et al., 2012) and thus, decrease the possibility of integration, and finally those that do not integrate into the host genome and are known as transgene-free. The transgene-free methods include mRNA (Warren and Wang, 2013), recombinant protein (Zhou et al., 2009) and Sendai virus (Fusaki et al., 2009). Delivering the pluripotency transcription factors as mRNA or recombinant protein is poorly effective and costly. In contrast, Sendai virus, is a highly effective RNA virus that efficiently reprogram different types of somatic cells.

Sendai is a cytoplasmic RNA replication incompetent virus $(\mathrm{SeV})$ that safely and effectively delivers the reprogramming factors into somatic cells, and does not integrate into the genome or alter the genetic 
information of the cell (Li et al., 2000; Fusaki et al., 2009). Furthermore, the virus is cleared out from the cells after a few passages assuring zero footprint of both the vectors and transgenes. The Sendai reprogramming system is commercially available as CytoTune iPS 2.0 for research purposes and as CTS CytoTune iPS 2.1 for clinical use. Both systems contain vectors encoding the four Yamanaka factors (OCT4, SOX2, KLF4, and C-MYC) optimized for generating iPSCs from human somatic cells, making Sendai virus the most rapid, efficient and cost-efficient method to generate transgene-free iPSCs.

Reliable and safe derivation of human iPSCs relies on the use of defined and qualified reagents that allow a smooth transition to downstream technologies and is compatible with GMP (Good Manufacture Practice) quality standards for large-scale cell production. Here we describe a reprogramming approach for human fibroblasts that uses a non-integrative system, chemically defined culture medium in feederfree conditions. This approach enables rapid, efficient, safe and reliable derivation of iPSCs compatible with future uses including genome editing and differentiation to a transplantable cell type.

\section{Materials and Reagents}

1. Falcon ${ }^{\circledast}$ 6-Well Flat-Bottom Plate, Tissue Culture-Treated (Falcon, catalog number: 38016)

2. Serological pipettes multiple sizes (Corning)

3. Falcon $15 \mathrm{ml}$ conical centrifuge tubes (Falcon, catalog number: 352097 )

4. Falcon $50 \mathrm{ml}$ conical centrifuge tubes (Falcon, catalog number: 352070 )

5. Cells: Human fibroblast expanded from skin biopsies preferentially at passage 1 to passage 5 . Early passage fibroblast can be obtained from a commercial source (i.e., ATCC), a repository (i.e., Corriell Institute) or expanded in the lab from skin biopsies (Vangipuram et al., 2013 describes the procedure in detail)

6. Corning ${ }^{\circledR}$ Matrige ${ }^{\circledR}$ hESC-Qualified Matrix (Corning, catalog number: 354277 )

7. CytoTune ${ }^{T M}$-iPS 2.0 Sendai Reprogramming Kit (Thermo Scientific, catalog number: A16518)

8. DMEM/F-12 (Gibco, catalog number: 11320033)

9. Fetal Bovine Serum (Gibco, catalog number: 16000044)

10. MEM NEAA (Gibco, catalog number: 11140050)

11. Pen Strep (Gibco, catalog number: 15-140-122)

12. mTeSR $^{\mathrm{TM}} 1$ (STEMCELL Technologies, catalog number: 85850)

13. TrypLE ${ }^{\text {TM }}$ Express Enzyme (1x) (Gibco, catalog number: 12605036)

14. Anti-Human TRA-1-60, Mouse monoclonal (Thermo Fisher Scientific, catalog number: 41-1000)

15. Anti-Human OCT4, Rabbit polyclonal, IgG1 (Abcam, catalog number: ab19857)

16. Anti-Human SOX2 Antibody, Rabbit polyclonal IgG1 (Abcam, catalog number: ab97959)

17. STEMdiff Trilineage Differentiation kit, STEMCELL Technologies, catalog number: 05230)

18. Universal Mycoplasma Detection Kit (ATCC, catalog number: 30-1012K)

19. Dulbecco's PBS (DPBS) without Calcium and Magnesium (Gibco, catalog number: 14190136)

20. Polybrene Hexadimethrine Bromide (Sigma-Aldrich, catalog number: H9268)

21. 0.5 M EDTA (Gibco, catalog number: 15575020) 
22. Fibroblast culture medium (see Recipes)

23. 5 mM EDTA solution (see Recipes)

24. $10 \mathrm{mM}$ Y27632 stock solution (see Recipes)

\section{Equipment}

1. Tissue culture incubator Heracell ${ }^{\mathrm{TM}}$ 150i (Thermo Fisher Scientific, catalog number: 51026283 )

2. Beckman Avanti J-30l Refrigerated with plate adapters (Beckman Coulter, catalog number: 17039)

3. Tissue culture laminar flow hood (NuAire Class II Type A2 NU-540)

4. Evos XL core microscope (Thermo Scientific, catalog number: AMEX1100)

5. Countess II FLAutomated Cell Counter (Thermo Fisher Scientific, catalog number: AMQAF1000)

6. Water bath Isotemp (Fisher Scientific, catalog number: S35936)

7. Portable Pipet-aid (Drummond, model: DP-101, catalog number: 4-000-101)

8. Micro pipettes (Eppendorf)

\section{Procedure}

\section{Day -1: Plate dermal fibroblast for reprogramming}

Use low-passage (passage 1 to 5 ) human fibroblasts for reprogramming experiments. The reprogramming efficiency decreases with each passage. Hence, we don't recommend reprogramming fibroblast after passage 6 . A schematic timeline and representative pictures can be seen in Figure 1.

1. Coat two wells of a 6 well plate with $2 \mathrm{ml}$ of $5 \mathrm{mg} / \mathrm{ml}$ Matrigel and make sure it covers the entire well. Incubate at $37^{\circ} \mathrm{C}$ for $30 \mathrm{~min}$.

2. Inspect the fibroblast culture for the desired confluency (more than $70 \%$ ), aspirate the culture medium and rinse twice with $2 \mathrm{ml}$ DPBS.

3. Add $500 \mu \mathrm{l} \mathrm{TrypLE}{ }^{\mathrm{TM}}$ Express enzyme and incubate at $37^{\circ} \mathrm{C}$ and $5 \% \mathrm{CO}_{2}$ for 2 to $5 \mathrm{~min}$ or until fibroblasts have detached. TrypLE ${ }^{\mathrm{TM}}$ is used because it has lower cell toxicity than standard Trypsin and it is an animal-free product.

4. Add $1 \mathrm{ml}$ fibroblast culture medium and transfer cell suspension to a $15-\mathrm{ml}$ conical tube.

5. Centrifuge at $200 \times g$ for $5 \mathrm{~min}$. Remove and discard supernatant.

6. Resuspend cells in $1 \mathrm{ml}$ of fresh fibroblast culture medium. Recipe available in the recipe section

7. Count fibroblasts using the desired method (e.g., Countess Automated Cell Counter), and plate $1 \times 10^{5}$ cells $/$ well $\left(10,000\right.$ cells $\left./ \mathrm{cm}^{2}\right)$ in the Matrigel-coated 6-well dish in $2 \mathrm{ml}$ of fibroblast culture medium.

8. Incubate $24 \mathrm{~h}$ at $37^{\circ} \mathrm{C}$ with a humidified atmosphere and $5 \% \mathrm{CO}_{2}$. 
A

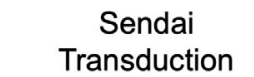

\begin{tabular}{|c|c|c|c|c|}
\hline $\begin{array}{l}\text { Plate } \\
\text { cells }\end{array}$ & $\begin{array}{l}\text { Change } \\
\text { medium }\end{array}$ & $\begin{array}{c}\text { Transition to } \\
\text { mTeSR1 }\end{array}$ & $\begin{array}{c}\text { Emerging } \\
\text { colonies } \\
\mid\end{array}$ & $\begin{array}{c}\text { Colonies ready } \\
\text { to pickup }\end{array}$ \\
\hline-3 & 0 & 4 & 12 & 21 \\
\hline
\end{tabular}

Fibroblast medium

mTeRS1

\section{Matrigel}

B

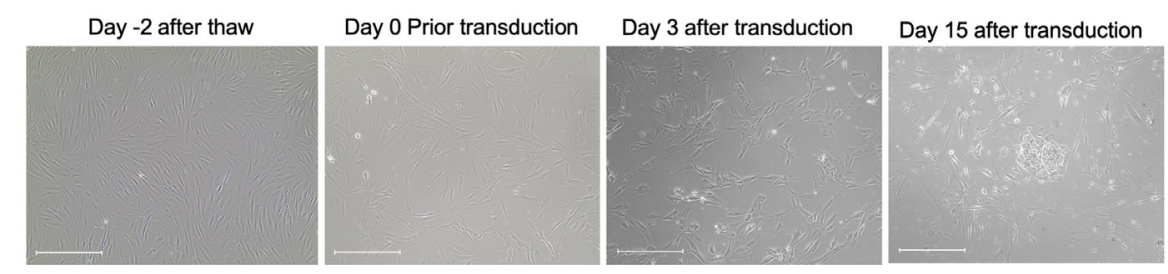

Figure 1. Derivation of induced pluripotent stem cells from fibroblast using Sendai virus and chemically defined medium. A. Schematic view of general reprogramming procedure including culture medium used. B. Images of fibroblast morphology changes during the early stages of reprogramming. Scale bars: $650 \mu \mathrm{m}$.

\section{Day 0: Transduction}

1. Inspect the fibroblast culture, proceed with transduction if cell density is approximately $40-50 \%$ confluent, and cells have fully adhered and extended. If those parameters are not meet, wait another $24 \mathrm{~h}$.

2. Warm $1 \mathrm{ml}$ of fibroblast culture medium in a water bath for each well to be transduced calculate the volume of each premade virus needed to reach a multiplicity of infection of (MOI) of 5:5:3 $(\mathrm{KOS} \mathrm{MOI}=5, \mathrm{hc}-\mathrm{Myc} \mathrm{MOI}=5$, hKIf4 $\mathrm{MOI}=3)$ using the live cell count from the day of the seeding, and the titer information on the CoA (calculate based on the lot number, the CoA can be download from thermofisher.com/cytotune). Calculate the volume of virus using the formula:

$$
\text { Volume of virus }(\mu \mathrm{l})=\frac{M O I\left(\frac{C I U}{\text { cell }}\right) \times \text { cell number }}{\text { titer of virus }\left(\frac{C I U}{m l}\right) \times 10^{-3}\left(\frac{m l}{\mu l}\right)}
$$

$\mathrm{CIU}=$ Cell infectious units

For example, to calculate the volume of hKOS virus with a titter of $1.1 \times 10^{8} \mathrm{CIU}$;

$$
\text { Volume of virus }(\mu \mathrm{l})=\frac{5\left(\frac{C I U}{\text { cell }}\right) \times 100,000}{1.1 \times 10^{8}\left(\frac{C I U}{\text { cell }}\right) \times 10^{-3}\left(\frac{\mathrm{ml}}{\mu l}\right)}=4.5 \mu \mathrm{l}
$$

3. Thaw one set of CytoTune ${ }^{\mathrm{TM}} 2.0$ Sendai aliquots from $-80{ }^{\circ} \mathrm{C}$ and briefly centrifuge the tube. Place it immediately on ice until ready to use. 
4. Add the calculated volumes of each of the three CytoTune ${ }^{\mathrm{TM}} 2.0$ Sendai virus to $1 \mathrm{ml}$ of prewarmed fibroblast culture medium.

5. OPTIONAL: Add $4 \mu \mathrm{g} / \mathrm{ml}$ of polybrene to the medium. Ensure that the solution of virus and polybrene is thoroughly mixed by pipetting the mixture gently up and down. Complete the next step within $5 \mathrm{~min}$. Polybrene increases the transduction efficiency of the virus, however, it can be toxic for some cell types. It neutralizes the charge repulsion between the virus and the cell surface increasing the overall transduction efficiency.

6. Aspirate the fibroblast culture medium from the cells, and add the reprogramming virus and polybrene mixture to the well containing the cells.

7. Close the 6-well dish, securely place on the plate adaptor, and centrifuge at 1,200 $\times g$ for $45 \mathrm{~min}$ at room temperature. Once the centrifugation is complete, add an additional $1 \mathrm{ml}$ of prewarm fibroblast culture medium.

8. Incubate the plate overnight in a $37{ }^{\circ} \mathrm{C}$ incubator with a humidified atmosphere of $5 \% \mathrm{CO}_{2}$.

\section{Day 1: Remove virus}

After $24 \mathrm{~h}$, aspirate medium with viruses and add $2 \mathrm{ml}$ fresh fibroblast culture medium. Expect to see cytotoxicity $24-48 \mathrm{~h}$ post-transduction, this is an indication of high uptake of the virus. See Figure 2.

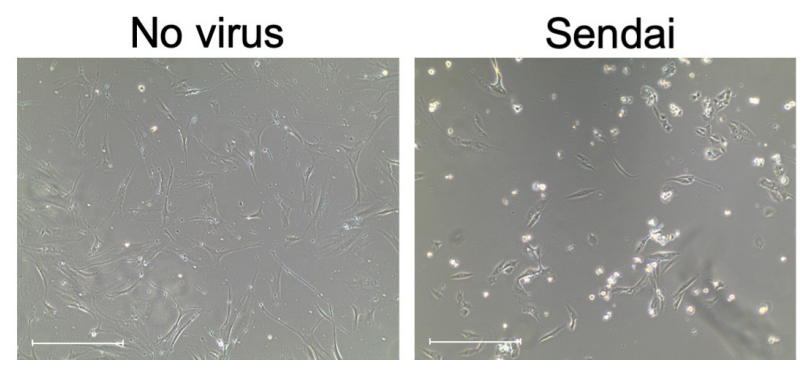

Figure 2. Images of morphological changes seventy-two hours after transduction with Sendai virus. Scale bars: $650 \mu \mathrm{m}$.

\section{Days 2 to 3}

Remove $2 \mathrm{ml}$ of used medium and add $2 \mathrm{ml}$ of fibroblast culture medium. Expect to see changes in cell morphology.

\section{Day 4: Transition to defined medium}

There are many different chemically defined culture medium commercially available for deriving and maintaining iPSCs. We have used mTeSR1 medium (Stem Cell Technologies), STEMFLEX (Life technologies) and mTeSR plus (Stem Cell Technologies) agnostically.

1. Remove $500 \mu \mathrm{l}$ of fibroblast culture medium and add $500 \mu \mathrm{l}$ of fresh mTeSR1. 


\section{Day 5}

1. Remove $1 \mathrm{ml}$ of culture medium and add $1 \mathrm{ml}$ of fresh $\mathrm{mTeSR} 1$.

\section{Day 6}

1. Remove $1.5 \mathrm{ml}$ of culture medium and add $1.5 \mathrm{ml}$ of fresh mTeSR1.

\section{Day 7}

Remove $2 \mathrm{ml}$ of medium culture medium and add the same volume of fresh mTeSR1.

\section{Days 8-20}

Feed cells daily with $2 \mathrm{ml}$ until colonies are ready to be passaged. Remove partially reprogrammed and differentiated colonies by scraping them before medium change. Fully reprogrammed colonies have round shape with well-defined borders, cells display identical morphology with a high ratio of nucleus to cytoplasm and prominent nucleoli. In contrast, partially reprogrammed colonies have undefined borders, an amorphous shape, and are composed of different types of cells.

\section{Day 21: First passage}

1. When colonies are ready to pick, prepare one Matrigel coated dish per colony to be passage, and incubate at $37^{\circ} \mathrm{C}$ for at least $30 \mathrm{~min}$.

2. Aspirate Matrigel from plates and add $2 \mathrm{ml} \mathrm{mTeSR} 1+10 \mu \mathrm{M} \mathrm{ROCK}$ inhibitor.

3. Use a 22 gauge needle or a pulled glass pipette to cut colonies in a grid-like pattern into small fragments. See Figure 3.

4. Use a $100 \mu \mathrm{l}$ pipettor to scrape fragments and collect them. Immediately transfer the fragments to the Matrigel coated plates with mTeSR $1+10 \mu \mathrm{M}$ ROCK inhibitor.

5. Rock plate back-and-forth and side-to-side to evenly distribute the cell fragments and incubate overnight at $37{ }^{\circ} \mathrm{C}$ with a humidified atmosphere of $5 \% \mathrm{CO}_{2}$.

6. Feed cells daily until ready to passage (usually every 6 to 7 days).

7. Repeat Steps 1 to 10 for 7 passages. We found that $>95 \%$ of the iPSCs clones at passage 7 , are transgene free.
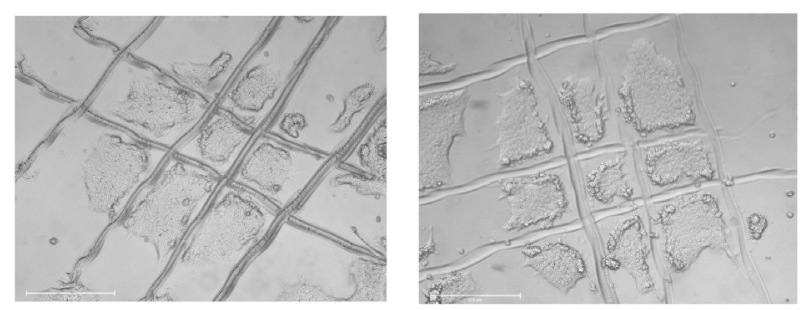

Figure 3. Images of colonies cut in a grid-like pattern into small fragments. Scale bars: $650 \mu \mathrm{m}$. 


\section{IPSCs cloning and expansion}

After passage 7, IPSCs are passage with EDTA buffer, as follow:

1. Coat 6 wells of a 6 -well tissue culture plate with Matrigel and place in incubate at $37^{\circ} \mathrm{C}$ for $30 \mathrm{~min}$

2. Prior to use, allow the Matrigel-coated plate to equilibrate to room temperature for at least $1 \mathrm{~h}$.

3. Just before dissociating cells for passaging, aspirate the liquid Matrigel solution from the wells and replace with $1 \mathrm{ml}$ of $\mathrm{mTeSR} 1+10 \mathrm{mM}$ Y27632 cell culture media per well. Set aside.

4. Wash the cells with $2 \mathrm{ml} 0.5 \mathrm{mM}$ EDTA, aspirate.

5. Add $2 \mathrm{ml}$ of room temperature $0.5 \mathrm{mM}$ EDTA solution to the cells.

6. Incubate the culture at $37^{\circ} \mathrm{C}$ for 3 to $5 \mathrm{~min}$, or until cells begin to separate uniformly throughout the entire colony. Do not allow the cultures detach in the EDTA solution.

7. As soon as the cells appear rounded and uniform separation is seen throughout the colonies, carefully aspirate the EDTA solution from the well. Do not rinse.

8. Immediately add $1 \mathrm{ml}$ of $\mathrm{mTeSR} 1+10 \mathrm{mM}$ Y27632. With a $5 \mathrm{ml}$ pipet, take up the $1 \mathrm{ml}$ of media from the well, and very gently dispense it against the culture surface to dissociate the cells from the dish. Repeat 1 to 2 more times, if needed.

9. Be careful not to over-pipet the cell suspension.

10. Dispense the cells gently into the $15 \mathrm{ml}$ conical tube containing an additional $3 \mathrm{ml}$ of pre-warmed media.

11. Pipet the solution very gently 1 time to mix, and dispense $1 \mathrm{ml}$ of the cell suspension drop-wise into each of the 6 new Matrigel-coated wells, and immediately rock plate back-and-forth and side-to-side to evenly distribute the colony pieces across the well.

12. Incubate undisturbed at $37^{\circ} \mathrm{C}$ and $5 \% \mathrm{CO}_{2}$ overnight.

13. Replace cell culture media every day with $2.5 \mathrm{ml}$ of fresh $\mathrm{mTeSR} 1$, warmed to room temperature.

14. Monitor cells daily and passage as needed.

\section{Characterization and cryopreservation}

Cells are expanded for cryopreservation at passage 10. Then, iPSCs are characterized (Figure 4) and prepare for downstream usage in genome engineering experiments or differentiation into specific cell types. Characterization includes:

1. Immunofluorescence staining of cell surface markers such Anti-Human TRA-1-60, Mouse monoclonal and transcription factors such as anti-Human OCT4, Rabbit polyclonal, IgG1 and anti-Human SOX2 Antibody, Rabbit polyclonal IgG1.

2. Pluripotency and trilineage differentiation capabilities (using the STEMdiff Trilineage Differentiation kit, and the Taqman hPSC Score card Panel.

3. Test for mycoplasma contamination using commercially available kits such as The Universal Mycoplasma Detection Kit.

4. G-banding Karyotype. 
A

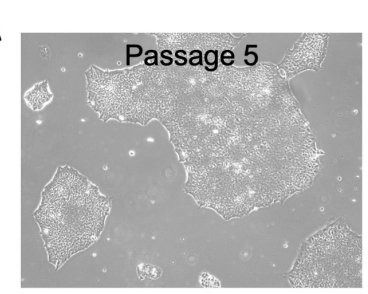

B

C

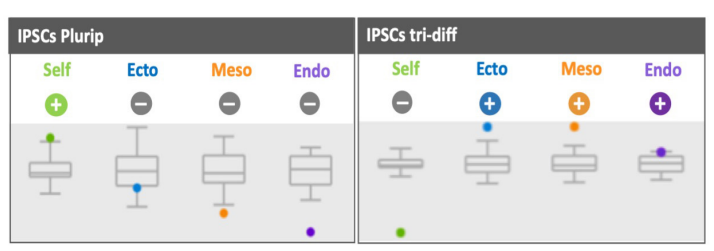

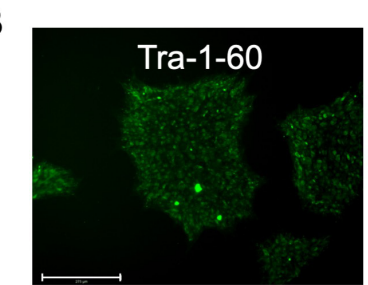

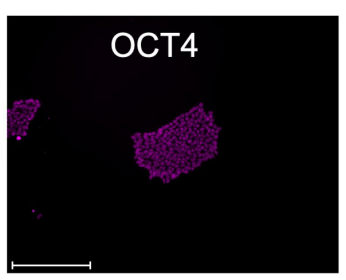

D

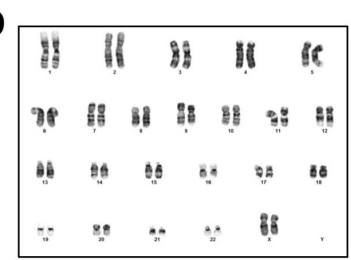

Figure 4. Characterization of iPSC derived from fibroblast. A. Bright field images of iPSCs, B. Immunofluorescence staining for pluripotency markers Tra-1-60 and OCT4. C. Taqman ScoreCard assay for pluripotent iPSCs (left panel) and iPSCs differentiated into endoderm, mesoderm and ectoderm (right panel). D. G-banding karyotype.

\section{Recipes}

1. Fibroblast culture medium

The following recipe is to prepare $500 \mathrm{ml}$ of fibroblast culture medium. Aseptically mix the following:

$445 \mathrm{ml}$ high glucose DMEM

$50 \mathrm{ml}$ heat-inactivated fetal bovine serum (FBS)

$5 \mathrm{ml}$ non-essential amino acids

2. $5 \mathrm{mM}$ EDTA solution

Dilute $0.5 \mathrm{ml}$ of $0.5 \mathrm{M}$ EDTA in $500 \mathrm{ml}$ DPBS without Calcium and Magnesium. Store at room temperature

3. $10 \mathrm{mM}$ Y27632 stock solution

Aseptically add $3.122 \mathrm{ml}$ of sterile water to $10 \mathrm{mg}$ of $\mathrm{Y} 27632$

Mix thoroughly by pipetting, aliquot in Eppendorf's and store at $-80^{\circ} \mathrm{C}$

Avoid repeated freezing and thawing

\section{Acknowledgments}

This protocol was developed as part of standard operations procedures of the Human Pluripotent Stem Cell core facility at UNC-CH. This work is supported by the UNC Office of Research. 
Please cite this article as: Beltran et. al., (2020). Derivation of Induced Pluripotent Stem Cells from Human Fibroblasts Using a Non-integrative System in

\section{Competing interests}

The authors do not have any financial or non-financial interest in the subject matter or materials discussed in this manuscript.

\section{Ethics}

This research was carried out in according with the UNC-CH institutional guidelines.

\section{References}

1. Fusaki, N., Ban, H., Nishiyama, A., Saeki, K. and Hasegawa, M. (2009). Efficient induction of transgene-free human pluripotent stem cells using a vector based on Sendai virus, an RNA virus that does not integrate into the host genome. Proc Jpn Acad Ser B Phys Biol Sci 85(8): 348-362.

2. Kane, N. M., Nowrouzi, A., Mukherjee, S., Blundell, M. P., Greig, J. A., Lee, W. K., Houslay, M. D., Milligan, G., Mountford, J. C., von Kalle, C., Schmidt, M., Thrasher, A. J. and Baker, A. H. (2010). Lentivirus-mediated reprogramming of somatic cells in the absence of transgenic transcription factors. Mol Ther 18(12): 2139-2145.

3. Li, H. O., Zhu, Y. F., Asakawa, M., Kuma, H., Hirata, T., Ueda, Y., Lee, Y. S., Fukumura, M., lida, A., Kato, A., Nagai, Y. and Hasegawa, M. (2000). A cytoplasmic RNA vector derived from nontransmissible Sendai virus with efficient gene transfer and expression. J Virol 74(14): 65646569.

4. Takahashi, K., Tanabe, K., Ohnuki, M., Narita, M., Ichisaka, T., Tomoda, K. and Yamanaka, S. (2007). Induction of pluripotent stem cells from adult human fibroblasts by defined factors. Cell 131(5): 861-872.

5. Takahashi, K. and Yamanaka, S. (2006). Induction of pluripotent stem cells from mouse embryonic and adult fibroblast cultures by defined factors. Cell 126(4): 663-676.

6. Vangipuram, M., Ting, D., Kim, S., Diaz, R. and Schüle, B. (2013). Affiliations expand Skin punch biopsy explant culture for derivation of primary human fibroblasts. $J$ Vis Exp (77): e3779.

7. Warren, L. and Wang, J. (2013). Feeder-free reprogramming of human fibroblasts with messenger RNA. Curr Protoc Stem Cell Biol 27: Unit 4A 6.

8. Weltner, J., Anisimov, A., Alitalo, K., Otonkoski, T. and Trokovic, R. (2012). Induced pluripotent stem cell clones reprogrammed via recombinant adeno-associated virus-mediated transduction contain integrated vector sequences. J Virol 86(8): 4463-4467.

9. Yu, J., Chau, K. F., Vodyanik, M. A., Jiang, J. and Jiang, Y. (2011). Efficient feeder-free episomal reprogramming with small molecules. PLoS One 6(3): e17557. 
10. Yu, J., Vodyanik, M. A., Smuga-Otto, K., Antosiewicz-Bourget, J., Frane, J. L., Tian, S., Nie, J., Jonsdottir, G. A., Ruotti, V., Stewart, R., Slukvin, II and Thomson, J. A. (2007). Induced pluripotent stem cell lines derived from human somatic cells. Science 318(5858): 1917-1920.

11. Zhou, H., Wu, S., Joo, J. Y., Zhu, S., Han, D. W., Lin, T., Trauger, S., Bien, G., Yao, S., Zhu, Y., Siuzdak, G., Scholer, H. R., Duan, L. and Ding, S. (2009). Generation of induced pluripotent stem cells using recombinant proteins. Cell Stem Cell 4(5): 381-384. 